\title{
An Effective Non-Traditional Algorithm for Solving the Problem of Optimal Power Flow with Minimum Environmental Pollution Using Price Penalty Factors
}

\author{
Mohammed Amine Meziane ${ }^{1}$ and Youssef Mouloudi ${ }^{2}$ \\ ${ }^{1,2}$ Dept. Science and Technology "Electrical Engineering", Faculty of Technology, \\ Tahri Mohammed University Bechar, Algeria BP 417, 08000 Bechar, Algeria \\ ${ }^{1}$ Laboratory of Analysis, Control and Optimization of Electro-Energetic Systems \\ (CAOSEE) \\ ${ }^{2}$ Smart Grids the renewable energies (ENERGARID) \\ Iaminemohmeziane@gmail.com, ${ }^{2}$ mouloudiyoussef@yahoo.fr
}

\begin{abstract}
Combined Economic and Emission Dispatch (CEED) problem is one of the important optimization problems concerning power system issues. The objective is to determine and provide an economic condition for generation units, subject to minimize the total fuel cost and environmental pollution caused by fossil based thermal generating units, founded on the generation and transmission constraints. In this paper, Particle Swarm Optimization (PSO) is proposed for solving the CEED problem under some equality and inequality constraints. The effect of four Price Penalty Factors (PPF)such as Min-Max, Max-Max, Min-Min and Max-Min price penalty factors are included in order to convert the biobjective problem into a single objective function. The validity of the proposed PSO based algorithm is demonstrated for three power system test cases: the IEEE 30-bus system with 6 generators, the 11 generation units system and the Real West Algeria power network consisting of 22 buses with 7 generators. The results are compared to data from SONELGAZ reported in a recent literature and it proves the feasibility of PSO based algorithm for the CEED problem.
\end{abstract}

Keywords: Combined Economic and Emission Dispatch, environmental pollution, practical swarm optimization, data from SONELGAZ, Real West Algeria electrical Network

\section{Introduction}

The Optimal Power Flow (OPF) problem is one of the key tools in operation and planning of modern electric utility grid. Operating at absolute minimum cost can no longer be the only criterion for dispatching electric power due to increasing concern over the environmental considerations. The generation of electricity from fossil fuel releases several contaminants, such as $\mathrm{SO}_{x}, \mathrm{NO}_{x}$ and $\mathrm{CO}_{2}$ into the atmosphere [1].

The global energy infra-structure depends heavily on burning fossil fuels which increases the emissions of several toxic gases like carbon dioxide $\left(\mathrm{CO}_{2}\right)$, sulphur dioxide $\left(\mathrm{SO}_{2}\right)$ and nitrogen oxide (NO), therefore, the environmental issue is, recently, taken into account as a part of the OPF problem and the goal, nowadays, is to minimize the cost and mitigate the emissions from the thermal power plants considering the equality and inequality constraints. The aforementioned approach is referred as the Combined Economic and Emission Dispatch problem.

Received (August 9, 2017), Review Result (December 14, 2017), Accepted (December 26, 2017) 
Modern Power systems consist of a large interconnected generation, transmission and distribution utilities, systems of such size leads to inevitable losses and the mitigation of these losses are targeted by lowering the production cost, maximizing reliability and by ensuring continuity of service.

The OPF problem summarize the different methods used to achieve the aforementioned goal and it was first discussed by Carpentier in 1962 [2], the main purpose of OPF is to find the optimal output power of generators to minimize the total generation cost and satisfy the equality and inequality constraints.

The traditional methods used to solve this economic load dispatch problem are the Lambda iteration method, Gradient, Newton, linear programming and interior point method. Recently, meta-heuristic techniques such as Simulated Annealing, Genetic Algorithm (GA), Particle Swarm Optimization (PSO), and Tabu search algorithm are used to solve this problem [3].

In this paper, Particle Swarm Optimization has been proposed to solve the CEED problem, using a price penalty factors based technique to convert the bi-objective CEED problem into a single objective function. The proposed algorithm has been implemented on three different test systems, the standard IEEE 30-bus, the Real west Algeria 22-bus system and eleven generators system. Satisfactory simulation results show the effectiveness of the proposed algorithm.

\section{Mathematical Formulation of CEED Problem}

\subsection{Economic Dispatch}

Generally, the OPF problem can be formulated as a constrained optimization, and the fuel cost function $\mathrm{F}_{\mathrm{i}}\left(\mathrm{P}_{\mathrm{i}}\right)$ of generating unit "i" usually can be expressed as a quadratic polynomial:

$$
\mathrm{F}_{\mathrm{c}}=\sum_{\mathrm{i}=1}^{\mathrm{ng}} \mathrm{F}_{\mathrm{i}}\left(\mathrm{P}_{\mathrm{Gi}}\right)=\sum_{\mathrm{i}=1}^{\mathrm{ng}}\left(\mathrm{a}_{\mathrm{i}} \mathrm{P}_{\mathrm{Gi}}^{2}+\mathrm{b}_{\mathrm{i}} \mathrm{P}_{\mathrm{Gi}}+\mathrm{c}_{\mathrm{i}}\right)
$$

Where, $\mathrm{F}_{\mathrm{c}}$ is total Fuel Cost; $\mathrm{F}_{\mathrm{i}}\left(\mathrm{P}_{\mathrm{Gi}}\right)$ Fuel cost of the $i_{\text {th }}$ generator; $\mathrm{P}_{\mathrm{Gi}}$ is real power generation of a generator unit $i ; \mathrm{a}_{\mathrm{i}} \mathrm{b}_{\mathrm{i}} \mathrm{c}_{\mathrm{i}}$ is cost coefficients of generating for the unit $i$ in $\left[\$ / \mathrm{MW}^{2} \mathrm{~h}\right],[\$ / \mathrm{MWh}]$ and $[\$ / \mathrm{h}]$ respectively; $n g$ is number of generating units.

\subsection{Emission Dispatch}

The problem for minimization of the quantity of the emissions is formulated by the following equation if the valve point effect is not taken into account.

$$
\mathrm{E}_{\mathrm{T}}=\sum_{\mathrm{i}=1}^{\mathrm{ng}}\left(\mathrm{d}_{\mathrm{i}} \mathrm{P}_{\mathrm{Gi}}^{2}+\mathrm{e}_{\mathrm{i}} \mathrm{P}_{\mathrm{Gi}}+\mathrm{f}_{\mathrm{i}}\right)
$$

Where, $E_{T}$ is total emission; $d_{i}, e_{i}, f_{i}$ is emission coefficients of generating unit iin $\left[\mathrm{kg} / \mathrm{MW}^{2} \mathrm{~h}\right],[\mathrm{kg} / \mathrm{MWh}]$ and $[\mathrm{kg} / \mathrm{h}]$ respectively.

\subsection{Constraints}

\subsubsection{Equality Constraint}

$$
\sum_{i=1}^{n} P_{i}=P_{G}=P_{D}+P_{L}
$$

Where, $\mathrm{P}_{\mathrm{G}}$ is total power generation of the system; $\mathrm{P}_{\mathrm{D}}$ is total demand of the system; $\mathrm{P}_{\mathrm{L}}$ is total transmission loss of the system

The transmission loss can be expressed as [4]: 


$$
\mathrm{P}_{\mathrm{L}}=\sum_{\mathrm{i}=1}^{\mathrm{n}} \sum_{\mathrm{i}=\mathrm{j}}^{\mathrm{n}} \mathrm{P}_{\mathrm{i}} \mathrm{B}_{\mathrm{ij}} \mathrm{P}_{\mathrm{j}}+\sum_{\mathrm{i}=1}^{\mathrm{n}} \mathrm{B}_{0 \mathrm{i}} \mathrm{P}_{\mathrm{i}}+\mathrm{B}_{00}
$$

Where, $\mathrm{P}_{\mathrm{i}}$ is active power generation of unit $I ; \mathrm{P}_{\mathrm{j}}$ is active power generation of unit $j ; \mathrm{B}_{\mathrm{ij}}$, $\mathrm{B}_{0 \mathrm{i}}, \mathrm{B}_{00}$ is transmission loss coefficients

\subsubsection{Inequality Constraints}

$$
P_{i, \min } \leq P_{i} \leq P_{i, \max }
$$

Where, $P_{i, \min }$ is minimum value of real power allowed at a generator $I ; P_{i, \max }$ is maximum value of real power allowed at a generator $i$

\subsection{Combined Economic and Emission Dispatch CEED}

Mathematic equation for CEED problem [5-7] is given by the objective functions (1) and (2).

The price penalty technique is used to convert the bi-objective optimization problem into a single objective optimization.

Then the CEED problem can be expressed as:

$$
F_{T}=\sum_{i=1}^{n g}\left[\left(\left(\mathrm{a}_{\mathrm{i}} \mathrm{P}_{\mathrm{Gi}}^{2}+\mathrm{b}_{\mathrm{i}} \mathrm{P}_{\mathrm{Gi}}+\mathrm{c}_{\mathrm{i}}\right)\right)+h_{i}\left(\left(\mathrm{~d}_{\mathrm{i}} \mathrm{P}_{\mathrm{Gi}}^{2}+\mathrm{e}_{\mathrm{i}} \mathrm{P}_{\mathrm{Gi}}+\mathrm{f}_{\mathrm{i}}\right)\right)\right]
$$

Where, $F_{T}$ is total CEED's fuel cost; $h_{i}$ is price penalty factor (PPF)

The CEED problem is formulated by the criterion (6) and under the constraints (3) to (5).

\subsection{Price Penalty Factors PPF}

The PPF [8-12] for CEED problem is formulated taking the ratio fuel cost and emission value of the corresponding generators as follows:

1) Min-Max price penalty factor is described as :

$$
h_{i}=\frac{\mathrm{a}_{\mathrm{i}} \mathrm{P}_{\mathrm{Gi} \text { min }}^{2}+\mathrm{b}_{\mathrm{i}} \mathrm{P}_{\mathrm{Gi}, \text { min }}+\mathrm{c}_{\mathrm{i}}}{\mathrm{d}_{\mathrm{i}} \mathrm{P}_{\mathrm{Gi}, \text { max }}^{2}+\mathrm{e}_{\mathrm{i}} \mathrm{P}_{\mathrm{Gi}, \text { max }}+\mathrm{f}_{\mathrm{i}}}
$$

2) Max-Max price penalty factor is described as :

$$
h_{i}=\frac{\mathrm{a}_{\mathrm{i}} \mathrm{P}_{\mathrm{Gi}, \text { max }}^{2}+\mathrm{b}_{\mathrm{i}} \mathrm{P}_{\mathrm{Gi} \text { max }}+\mathrm{c}_{\mathrm{i}}}{\mathrm{d}_{\mathrm{i}} \mathrm{P}_{\mathrm{Gi}, \text { max }}^{2}+\mathrm{e}_{\mathrm{i}} \mathrm{P}_{\mathrm{Gi} \text { max }}+\mathrm{f}_{\mathrm{i}}}
$$

3) Min-Min price penalty factor is described as :

$$
h_{i}=\frac{\mathrm{a}_{\mathrm{i}} \mathrm{P}_{\mathrm{Gi}, \text { min }}^{2}+\mathrm{b}_{\mathrm{i}} \mathrm{P}_{\mathrm{Gi}, \text { min }}+\mathrm{c}_{\mathrm{i}}}{\mathrm{d}_{\mathrm{i}} \mathrm{P}_{\mathrm{Gi}, \text { min }}^{2}+\mathrm{e}_{\mathrm{i}} \mathrm{P}_{\mathrm{Gi}, \text { min }}+\mathrm{f}_{\mathrm{i}}}
$$

4) Max-Min price penalty factor is described as :

$$
h_{i}=\frac{\mathrm{a}_{\mathrm{i}} \mathrm{P}_{\mathrm{Gi}, \text { max }}^{2}+\mathrm{b}_{\mathrm{i}} \mathrm{P}_{\mathrm{Gi}, \text { max }}+\mathrm{c}_{\mathrm{i}}}{\mathrm{d}_{\mathrm{i}} \mathrm{P}_{\mathrm{Gi} \text {,min }}^{2}+\mathrm{e}_{\mathrm{i}} \mathrm{P}_{\mathrm{Gi}, \text { min }}+\mathrm{f}_{\mathrm{i}}}
$$

\section{Overview of Basic PSO Algorithm}

The PSO is a population based stochastic optimization technique, was first introduced by James Kennedy and Russell Eberhart in the USA, and is one of modern heuristic algorithms [13].

Inspired from two concepts [14]:

$\checkmark$ The observation of swarming habits of animals such as birds or fish. 
$\checkmark$ The field of evolutionary computation (such as genetic algorithms).

\subsection{PSO Concepts}

$\checkmark$ The PSO algorithm maintains multiple potential solutions at one time.

$\checkmark$ During each iteration of the algorithm, each solution is evaluated by an objective function to determine its fitness.

$\checkmark$ Each solution is represented by a particle in the fitness landscape (search space).

$\checkmark$ The particles "fly" or "swarm" through the search space to find the maximum value returned by the objective function.

\subsection{Maintained Information}

Each particle maintains:

$\checkmark$ Position in the search space (solution and fitness).

$\checkmark$ Velocity.

$\checkmark$ Individual best position.

In addition, the swarm maintains its global best position.

\subsection{Canonical PSO Algorithm}

The PSO algorithm consists of just three steps:

$\checkmark$ Evaluate fitness of each particle.

$\checkmark$ Update individual and global bests.

$\checkmark$ Update velocity and position of each particle.

These steps are repeated until some stopping condition is met.

\subsection{Velocity Update}

Each particle's velocity is updated using this equation:

$$
V_{i}(t+1)=\omega V_{i}(t)+c_{1} r_{1}\left[\text { Pbest }_{i}(t)-X_{i}(t)\right]+c_{2} r_{2}\left[\text { Gbest }_{i}(t)-X_{i}(t)\right]
$$

Where, $i$ is the particle index; $\omega$ is the inertia coefficient; $c_{1}, c_{2}$ are acceleration coefficients $0 \leq c_{1}, c_{2} \leq 2 ; r_{1}, r_{2}$ are random values, $0 \leq r_{1}, r_{2} \leq$ regenerated every velocity update; $V_{i}$ is the particle's velocity at time $\mathrm{t} ; X_{i}$ is the particle's position at time $\mathrm{t}$; $P_{\text {best }}$ is the particle's individual best solution as of time $\mathrm{t} ; G_{\text {best }}$ is the swarm's best solution as of time $t$.

\subsection{Velocity Update - Inertial Component}

Keeps the particle moving in the same direction it was originally heading

$\checkmark$ Inertia coefficient $\omega$ usually between 0.8 and 1.2

$\checkmark$ Lower values speed up convergence, higher values encourage exploring the search space

\subsection{Velocity Update - Cognitive Component}

Acts as the particle's memory, causing it to return to its individual best regions of the search space

$\checkmark$ Cognitive coefficient c1 usually close to 2 
$\checkmark$ Coefficient limits the size of the step the particle takes toward its individual best $P_{\text {best }}$

\subsection{Velocity Update - Social Component}

$\checkmark$ Causes the particle to move to the best regions the swarm has found so far

$\checkmark$ Social coefficient c2 usually close to 2

$\checkmark$ Coefficient limits the size of the step the particle takes toward the global best $G_{\text {best }}$

\subsection{Position Update}

Each particle's position is updated using this equation:

$$
X_{i}(t+1)=X_{i}(t)+V_{i}(t+1)
$$

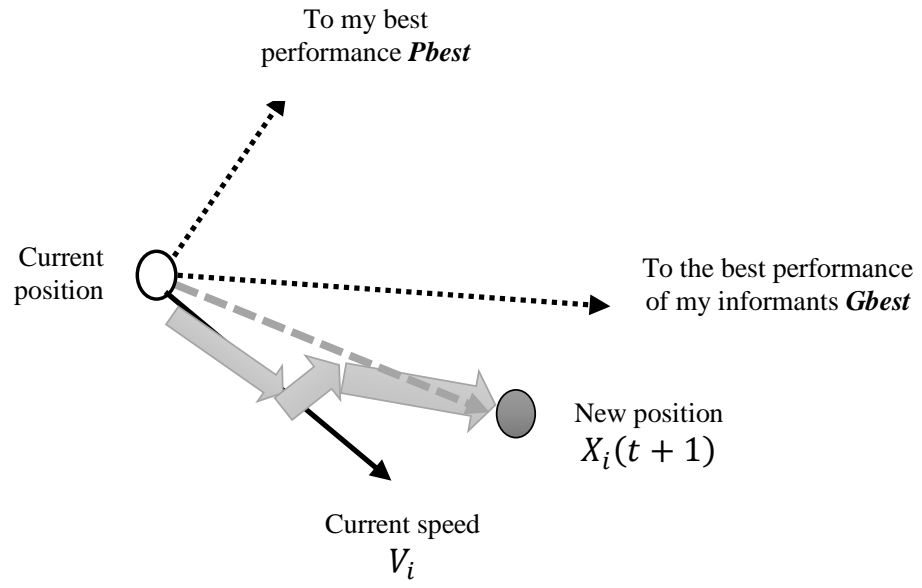

Figure 1. Simple Schematic Diagram of the Displacement of a Simple Particle

To achieve its next move, each particle combines three trends:

Follow its own speed, Return to its best performance, Go to the best performance of its informants (Figure 1).

\section{PSO Algorithm for Solution of the CEED Problem}

The fuel cost equation is given in (1) and is solved subject to the constraints (3), (4), and (5). The emission function is given in (2) and the price penalty factors (7) to (10) are used to formulate the single objective function (6) of the CEED problem.

The above problem is solved by the application of PSO algorithm, which is adopted to incorporate the specifics of the CEED problem. This is done by the following way shown in the Flowchart of the PSO algorithm (Figure 2): 


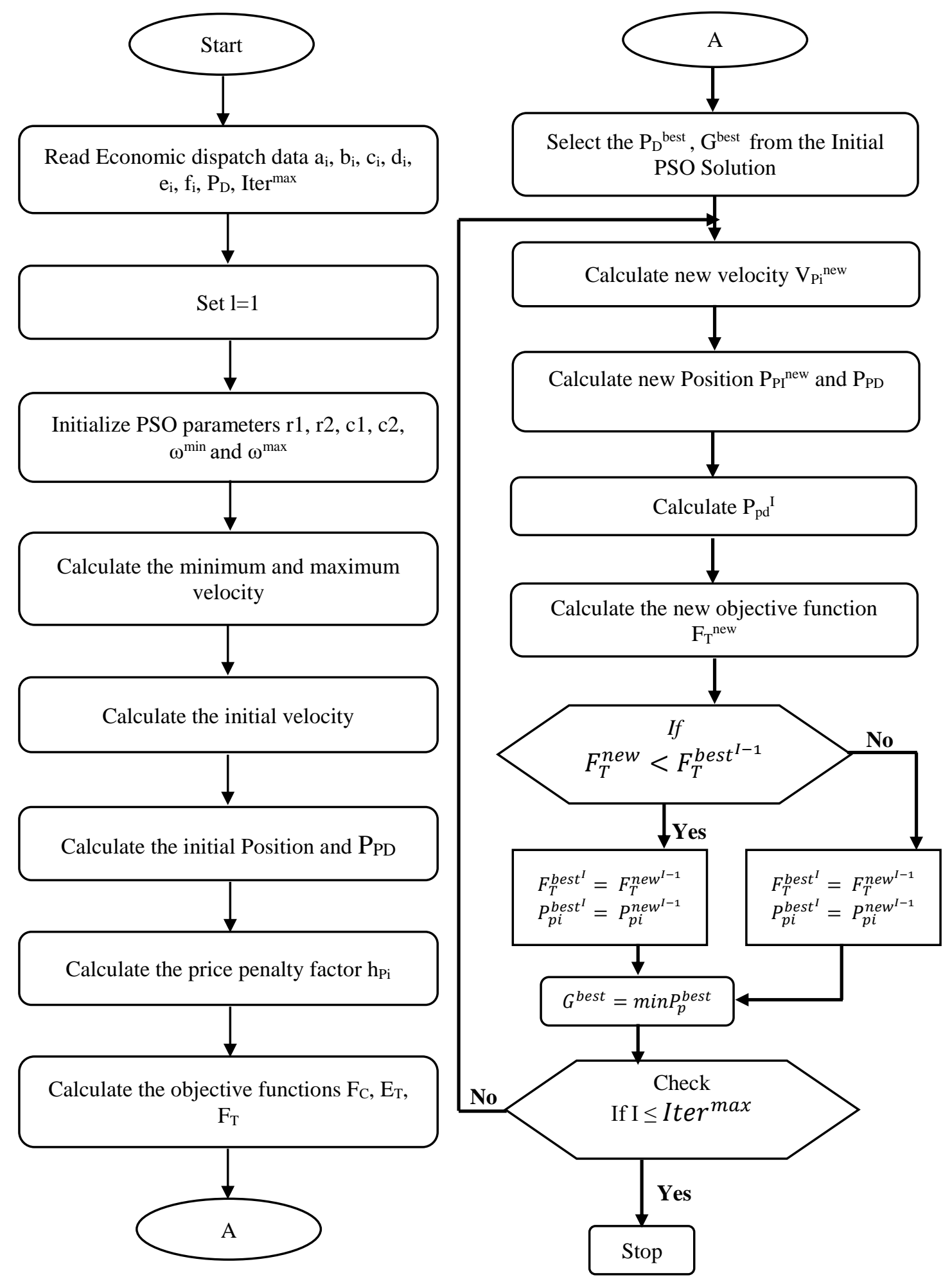

Figure 2. Flowchart for the Proposed Application of PSO Algorithm for CEED Problem Solution 
The optimal setting of the PSO control parameters are given in the Table 1 below:

Table 1. The Initial Setting of the PSO Control Parameters

\begin{tabular}{|l|c|}
\hline Minimum weight $\omega_{\min }$ & 0.4 \\
\hline Maximum weight $\omega_{\max }$ & 0.9 \\
\hline Weight $\omega$ & 0.65 \\
\hline Acceleration factors $c_{1}, c_{2}$ & 0.7, \\
\hline Total number of iterations $m$ & 0.6 \\
\hline $\begin{array}{l}\text { Total number of particles in the swarm } \\
N_{P}\end{array}$ & 25 \\
\hline
\end{tabular}

\section{Simulation, Numerical Result and Discussion}

Here, the results of two different case studies have been brought to verify and show the feasibility of the proposed PSO algorithm to solve the CEED problem.

The programming of the CEED using the PSO method has been applied by the use of the MATLAB software environment, tested on a CORE i5, personal computer with 2.20 GHz and 4 GO RAM.

\subsection{Application Study}

The PSO algorithm shown in the previous flowchart is applied to solve the CEED problem for IEEE 30-bus system (Figure 3) and real oust Algeria 22-bus system (Figure 12).

\subsubsection{Case study 1: IEEE 30-Bus System with 6 Generators}

The system has the total load demand of 250 [MW]. Table2 present data of fuel cost and generator limits. The emission coefficients of generatorsare given in Table 3. While Table 4show the transmission loss coefficient for the considered system.

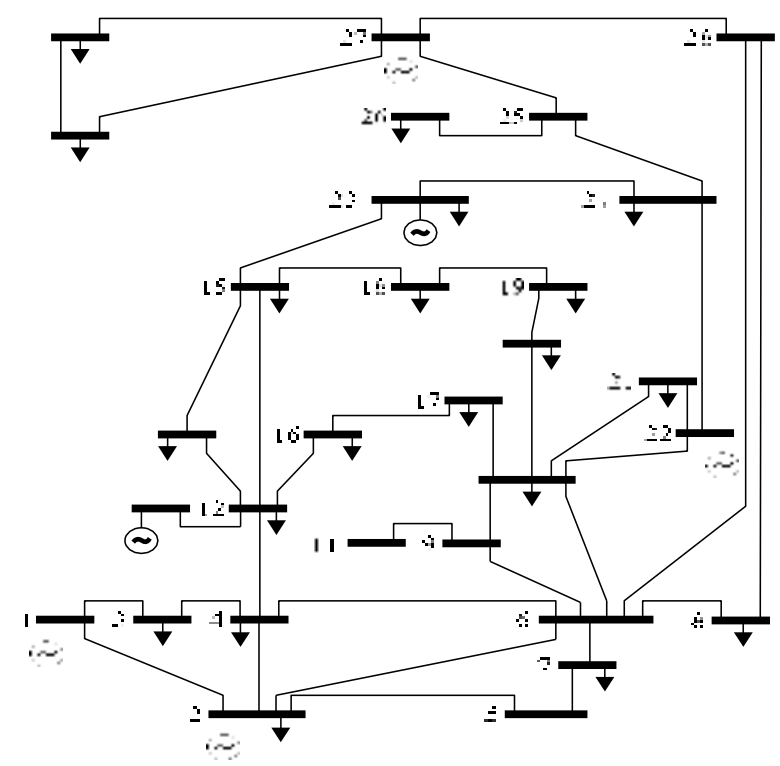

Figure 3. Single Line Diagram of the IEEE 30-Bus Test System 
Table 2. Power Generation Limits and Cost Coefficients for IEEE 30-Bus System

\begin{tabular}{|c|c|c|c|c|c|}
\hline Bus & $\begin{array}{c}P_{G, \max }[\mathrm{M} \\
\mathrm{W}]\end{array}$ & $\begin{array}{c}P_{G, \min }[\mathrm{M} \\
\mathrm{W}]\end{array}$ & $\begin{array}{c}\mathrm{a}_{\mathrm{i}}[\$ / \mathrm{MW} \\
\left.{ }^{2} \mathrm{~h}\right]\end{array}$ & $\begin{array}{c}\mathrm{b}_{\mathrm{i}}[\$ / \mathrm{M} \\
\mathrm{Wh}]\end{array}$ & $\begin{array}{c}\mathrm{c}_{\mathrm{i}}[\$ / \\
\mathrm{h}]\end{array}$ \\
\hline 1 & 200 & 50 & 0.00375 & 2.00 & 0 \\
\hline 2 & 80 & 20 & 0.01750 & 1.70 & 0 \\
\hline 5 & 50 & 15 & 0.06250 & 1.00 & 0 \\
\hline 8 & 35 & 10 & 0.00824 & 3.25 & 0 \\
\hline 11 & 30 & 10 & 0.02500 & 3.00 & 0 \\
\hline 13 & 40 & 12 & 0.02500 & 3.00 & 0 \\
\hline
\end{tabular}

Table 3. Pollution Coefficients for the IEEE 30-Bus System

\begin{tabular}{|l|c|c|c|}
\hline Bus & $\mathrm{d}_{\mathrm{i}}[\mathrm{kg} / \mathrm{MW}$ & $\begin{array}{c}\mathrm{e}_{\mathrm{i}}[\mathrm{kg} / \mathrm{M} \\
\mathrm{Wh}]\end{array}$ & $\mathrm{f}_{\mathrm{i}}[\mathrm{kg} / \mathrm{h}]$ \\
\hline 1 & 0.0126 & -0.90 & 22.983 \\
\hline 2 & 0.0200 & -0.10 & 25.313 \\
\hline 5 & 0.0270 & -0.01 & 25.505 \\
\hline 8 & 0.0291 & -0.005 & 24.900 \\
\hline 11 & 0.0290 & -0.004 & 24.700 \\
\hline 13 & 0.0271 & -0.0055 & 25.300 \\
\hline
\end{tabular}

Table 4. Transmission Loss Coefficients

\begin{tabular}{|c|c|c|c|c|c|}
\hline \multicolumn{6}{|c|}{ B } \\
\hline 0.000218 & 0.000103 & 0.000009 & -0.000010 & 0.000002 & 0.000027 \\
\hline 0.000103 & 0.000181 & 0.000004 & -0.000015 & 0.000002 & 0.000030 \\
\hline 0.000009 & 0.000004 & 0.000417 & -0.000131 & -0.000153 & -0.000107 \\
\hline 0.000010 & -0.000015 & -0.000131 & 0.000221 & 0.000094 & 0.000050 \\
\hline 0.000002 & 0.000002 & -0.000153 & 0.000094 & 0.000243 & -0.000001 \\
\hline 0.000027 & 0.000030 & -0.000107 & 0.000050 & -0.000001 & 0.0003458 \\
\hline \multicolumn{3}{|c|}{$\mathrm{B}_{0}$} & \multicolumn{2}{|c|}{$B_{00}=0.000014$} & \\
\hline 0.000003 & 0.000021 & -0.00056 & & & \\
\hline 0.000034 & 0.000015 & 0.000078 & & & \\
\hline
\end{tabular}

The results, including the optimal values of the generated power, generation cost, the emission level and power losses are reported in Table5 for all the price penalty factor. Figure 4-11 illustrates the convergence property of the proposed algorithm for case study 1. 
Table 5. The Best Obtained Results of IEEE 30-Bus System

\begin{tabular}{|l|c|c|c|c|}
\hline \multicolumn{1}{|c|}{ criterion } & Min-Max & Max-Max & Min-Min & Max-Min \\
\hline $\boldsymbol{P}_{\mathbf{1}}[\mathbf{M W}]$ & 107.8 & 80.906 & 58.702 & 54.674 \\
\hline $\boldsymbol{P}_{\mathbf{2}}[\mathbf{M W}]$ & 43.792 & 52.296 & 63.827 & 59.209 \\
\hline $\boldsymbol{P}_{\mathbf{3}}[\mathbf{M W}]$ & 35.277 & 51.385 & 51.416 & 42.094 \\
\hline $\boldsymbol{P}_{\mathbf{4}}[\mathbf{M W}]$ & 21.718 & 34.126 & 25.048 & 36.58 \\
\hline $\boldsymbol{P}_{\mathbf{5}}[\mathbf{M W}]$ & 23.374 & 14.878 & 21.466 & 30.063 \\
\hline $\boldsymbol{P}_{\mathbf{6}}[\mathbf{M W}]$ & 22.606 & 20.213 & 32.953 & 30.378 \\
\hline $\begin{array}{l}\text { Transmission } \\
\text { Loss }\end{array}$ & 4.5703 & $\mathbf{3 . 8 0 3 3}$ & $\mathbf{3 . 4 2 2 3}$ & $\mathbf{2 . 9 9 8 9}$ \\
\hline Total output & 256.18 & 255.53 & 256.19 & 254.65 \\
\hline Load demand & 250 & 250 & 250 & 250 \\
\hline Fuel Cost [\$/h] & $\mathbf{7 2 1 . 3 3}$ & 783.79 & 818.56 & 795.4 \\
\hline Emission [kg/h] & $\mathbf{2 7 9 . 8 5}$ & 305.3 & 325.79 & 319.65 \\
\hline Total Cost [\$/h] & $\mathbf{8 4 4 . 2 1}$ & 1429.6 & 834.93 & 2266.1 \\
\hline Temps [S] & $\mathbf{0 . 2 6 1 6 6 9}$ & 0.243196 & 0.303118 & 0.272172 \\
\hline
\end{tabular}

Table 6. Graphical Representation of the Best-Obtained Simulink Results for IEEE 30-Bus System

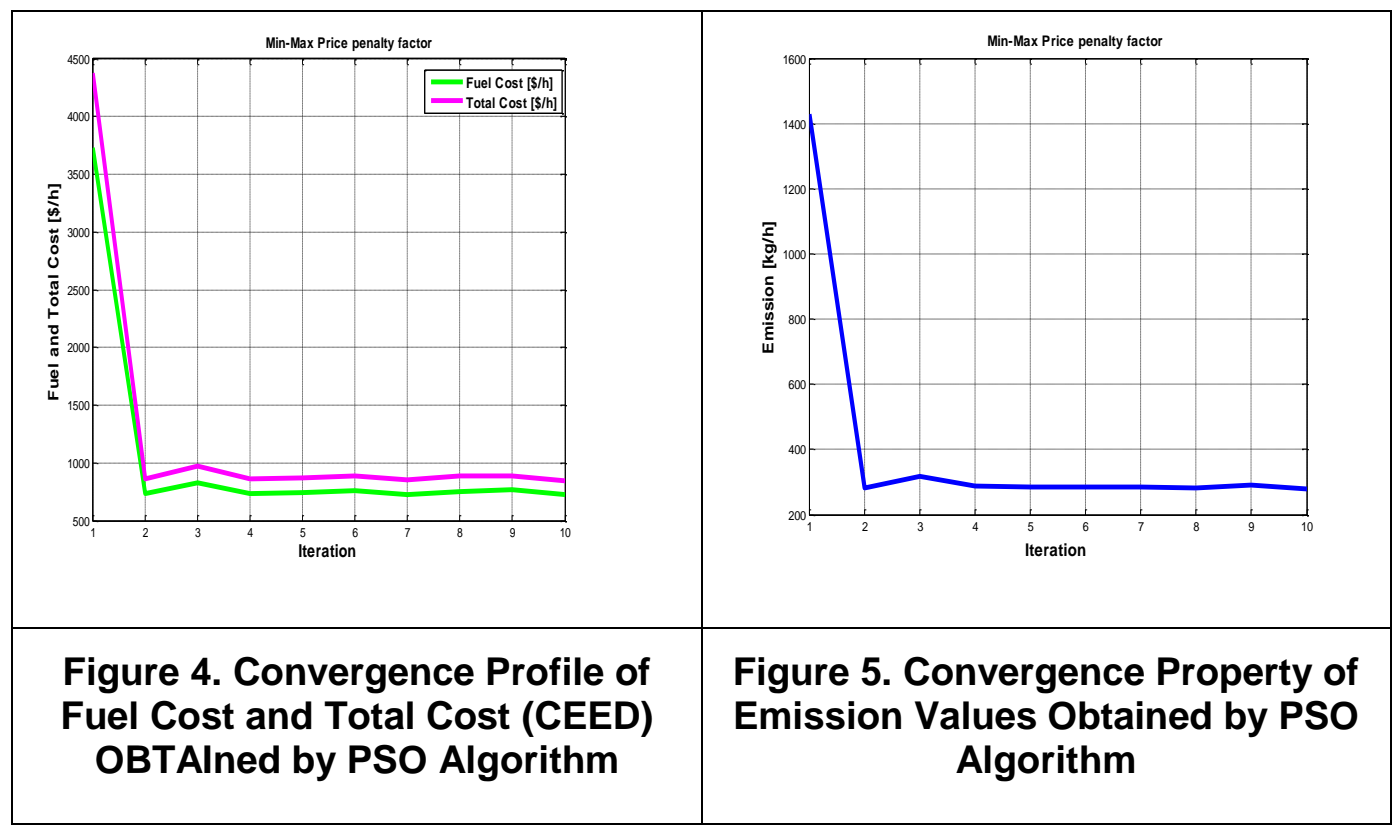




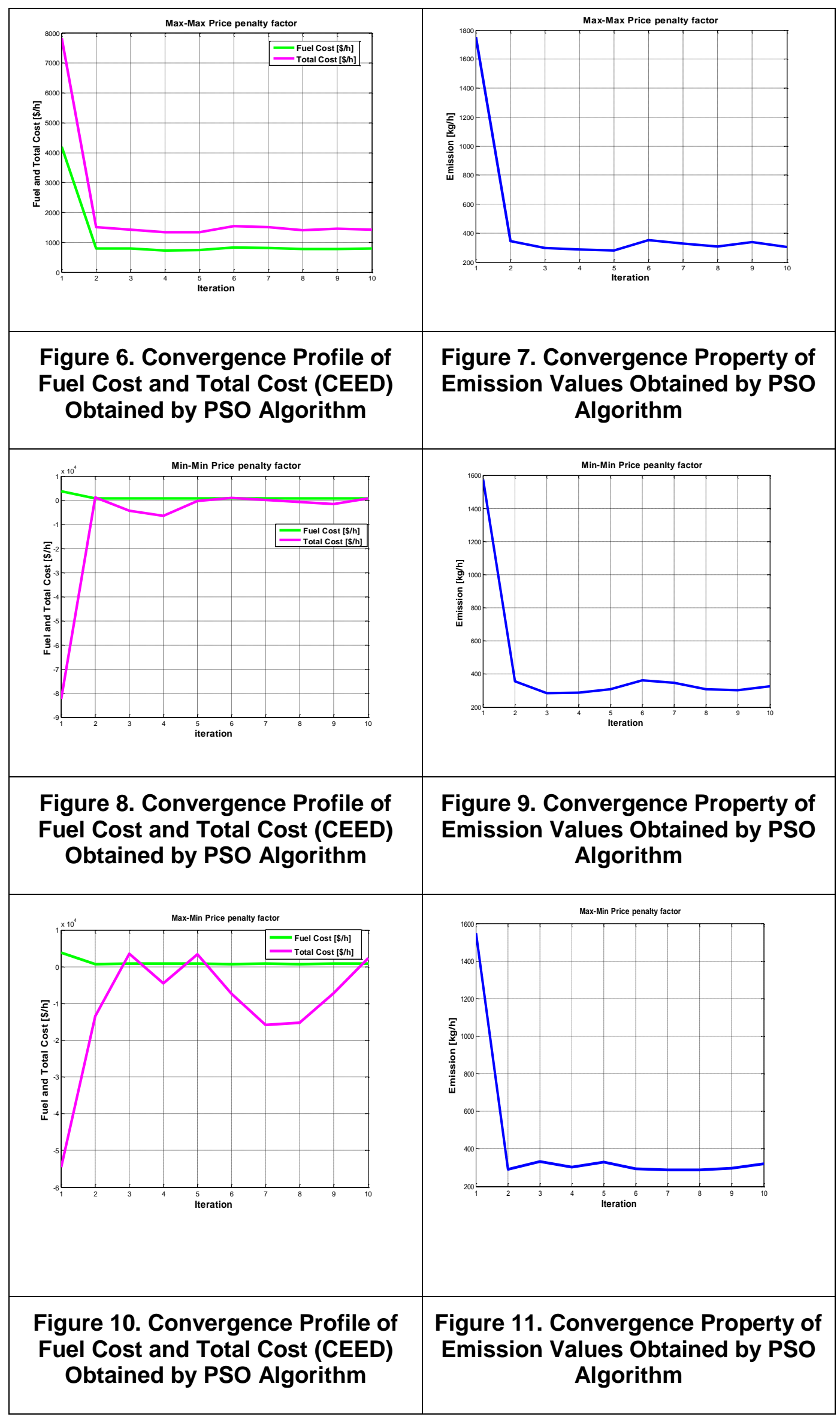


As illustrated in Table 5 the active powers of the 6 generators are all within their allowable limits.

PSO algorithm using Min-Max Price penalty factor gives minimum fuel cost, pollution control and total fuel cost CEED, with acceptable computation time. When using the Max-Max, Min-Min, Max-Min penalty factor the transmission power loss value is less in comparison with the Min-Max penalty factor, which demonstrates the ability of the PSO algorithm to find the optimal points in a search space, since meta-heuristic PSO generate random solution for each execution.

Figure 4 and 5 shows the convergence for the best solutions of the minimum fuel and total cost. It can be seen that the convergence of PSO when using Min-Max price penalty factor is faster and more effective than the other price penalty factor, for example at the iteration 2 the fuel and total cost by Min-Max price penalty factor is lower than those obtained by other Price penalty factor. And this applies to emission values.

\subsubsection{Case study 2: Real West Algeria 22-Bus System with 7 Generators}

The proposed PSO algorithm is tested for solving the CEED problem in power network real, West Algeria (Figure 12).

The test system consists of 7 thermal units, 15 load buses and 31 transmission lines, 03compensator var static SVC [3* (+40Mvar et )10Mvar)]. The total system demand is $856 \mathrm{MW}$.

Table 7. Power Generation Limits and Cost Coefficients for the 22-Bus Power Network Real, West Algeria 220 kv

\begin{tabular}{|l|l|l|l|l|l|}
\hline Bus & $P_{G, \max }[\mathrm{MW}]$ & $P_{G, \min }[\mathrm{MW}]$ & $\mathrm{a}_{\mathrm{i}}\left[\$ / \mathrm{MW}^{2} \mathrm{~h}\right]$ & $\mathrm{b}_{\mathrm{i}}[\$ / \mathrm{MWh}]$ & $\mathrm{c}_{\mathrm{i}}[\$ / \mathrm{h}]$ \\
\hline 1 & 500 & 100 & 0.007 & 7.5 & 240 \\
\hline 2 & 200 & 50 & 0.008 & 7 & 200 \\
\hline 3 & 300 & 80 & 0.0085 & 7.5 & 220 \\
\hline 4 & 150 & 50 & 0.009 & 7 & 200 \\
\hline 5 & 200 & 50 & 0.009 & 9 & 220 \\
\hline 6 & 120 & 50 & 0.0075 & 10 & 190 \\
\hline 7 & 80 & 10 & 0.009 & 6.3 & 180 \\
\hline
\end{tabular}

The best solutions of solving this problem by the proposed algorithm are shown in Table 8 . The obtained results satisfy the desired generating unit's constraints. The convergence property of the algorithm for all the price penalty factor is illustrated in figure (13-20). 


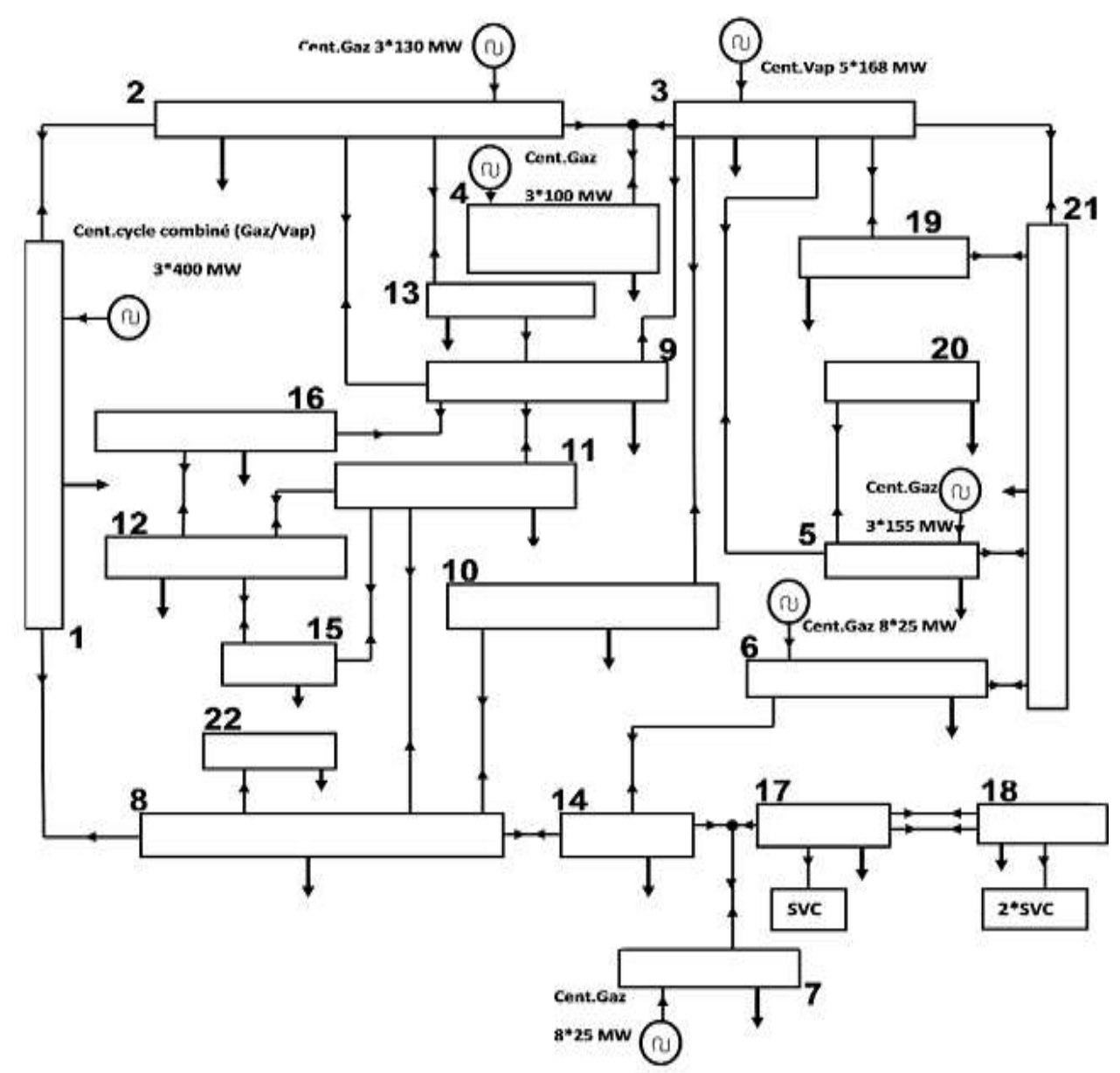

Figure 12. Power Network Real, West Algeria 220kV of the 22-Bus

Table 8. The Best Obtained Results of 22-Bus Power Network Real, West Algeria $220 \mathrm{kv}$

\begin{tabular}{|l|c|c|c|c|c|}
\hline \multicolumn{1}{|c|}{ criterion } & Min-Max & $\begin{array}{c}\text { Data Frome } \\
\text { SONELGAZ } \\
{[\mathbf{1 5}]}\end{array}$ & Max-Max & Min-Min & Max-Min \\
\hline $\boldsymbol{P}_{\mathbf{1}}[\mathbf{M W}]$ & 100 & 200 & 100 & 100 & 100 \\
\hline $\boldsymbol{P}_{\mathbf{2}}[\mathbf{M W}]$ & 185.69 & 200 & 123.65 & 161.14 & 121.93 \\
\hline $\boldsymbol{P}_{\mathbf{3}}[\mathbf{M W}]$ & 191.72 & 300 & 277.09 & 231.07 & 247.96 \\
\hline $\boldsymbol{P}_{\mathbf{4}}[\mathbf{M W}]$ & 132.13 & 80 & 107.34 & 113.5 & 142.47 \\
\hline $\boldsymbol{P}_{\mathbf{5}}[\mathbf{M W}]$ & 96.892 & 100 & 89.872 & 123.92 & 118.64 \\
\hline $\boldsymbol{P}_{\mathbf{6}}[\mathbf{M W}]$ & 111.23 & 100 & 103.75 & 88.754 & 90.348 \\
\hline $\boldsymbol{P}_{\mathbf{7}}[\boldsymbol{M W}]$ & 46.767 & 10 & 62.762 & 64.689 & 61.832 \\
\hline $\begin{array}{l}\text { Transmission } \\
\text { Loss }\end{array}$ & $\mathbf{1 8 . 4}$ & $\mathbf{2 1 . 4}$ & $\mathbf{2 1 . 9}$ & $\mathbf{2 1 . 2}$ & $\mathbf{2 2 . 6}$ \\
\hline Total output & 864.429 & 990 & 864.464 & 865.073 & 883.18 \\
\hline Load demand & 856 & 856 & 856 & 856 & 856 \\
\hline
\end{tabular}




\begin{tabular}{|l|c|c|c|c|c|}
\hline $\begin{array}{l}\text { Fuel Cost } \\
{[\mathbf{\$} / \mathrm{h}]}\end{array}$ & $\mathbf{8 9 1 5}$ & $\mathbf{9 1 0 4 . 4 2}$ & 9044.6 & 9068.4 & 9131.4 \\
\hline $\begin{array}{l}\text { Emission } \\
{[\mathbf{k g} / \mathrm{h}]}\end{array}$ & $\mathbf{2 9 3 8 . 2}$ & $/$ & 3385.6 & 3140.8 & 3324.3 \\
\hline $\begin{array}{l}\text { Total Cost } \\
{[\mathbf{\$} / \mathbf{h}]}\end{array}$ & $\mathbf{1 1 1 0 4}$ & $/$ & 15465 & 28595 & 75071 \\
\hline Temps [S] & 0.248867 & $/$ & 0.241306 & 0.249231 & 0.254852 \\
\hline
\end{tabular}

Table 9. Graphical Representation of the Best Obtained Simulink Results for 22-Bus Power Network Real, West Algeria 220 kv

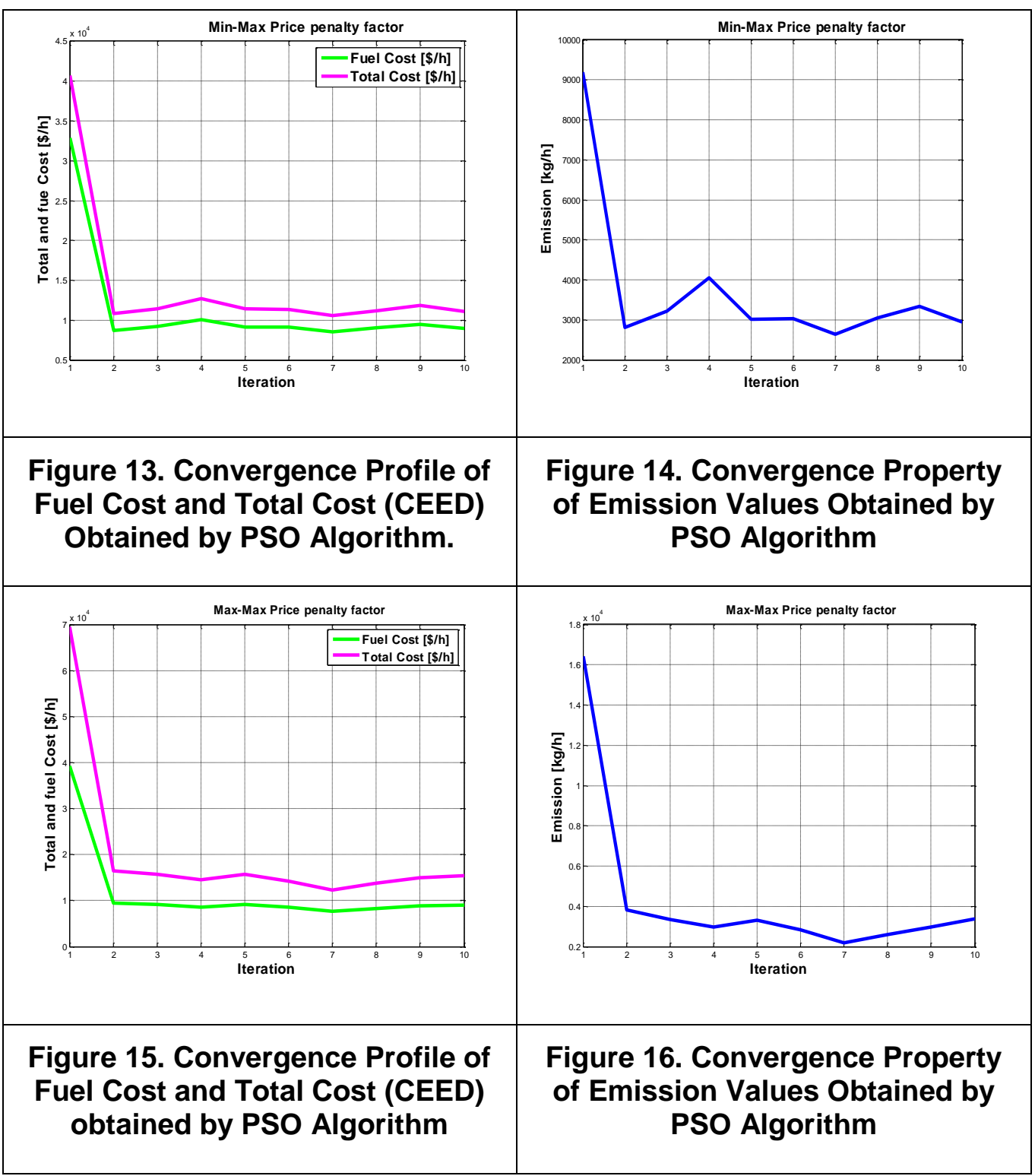




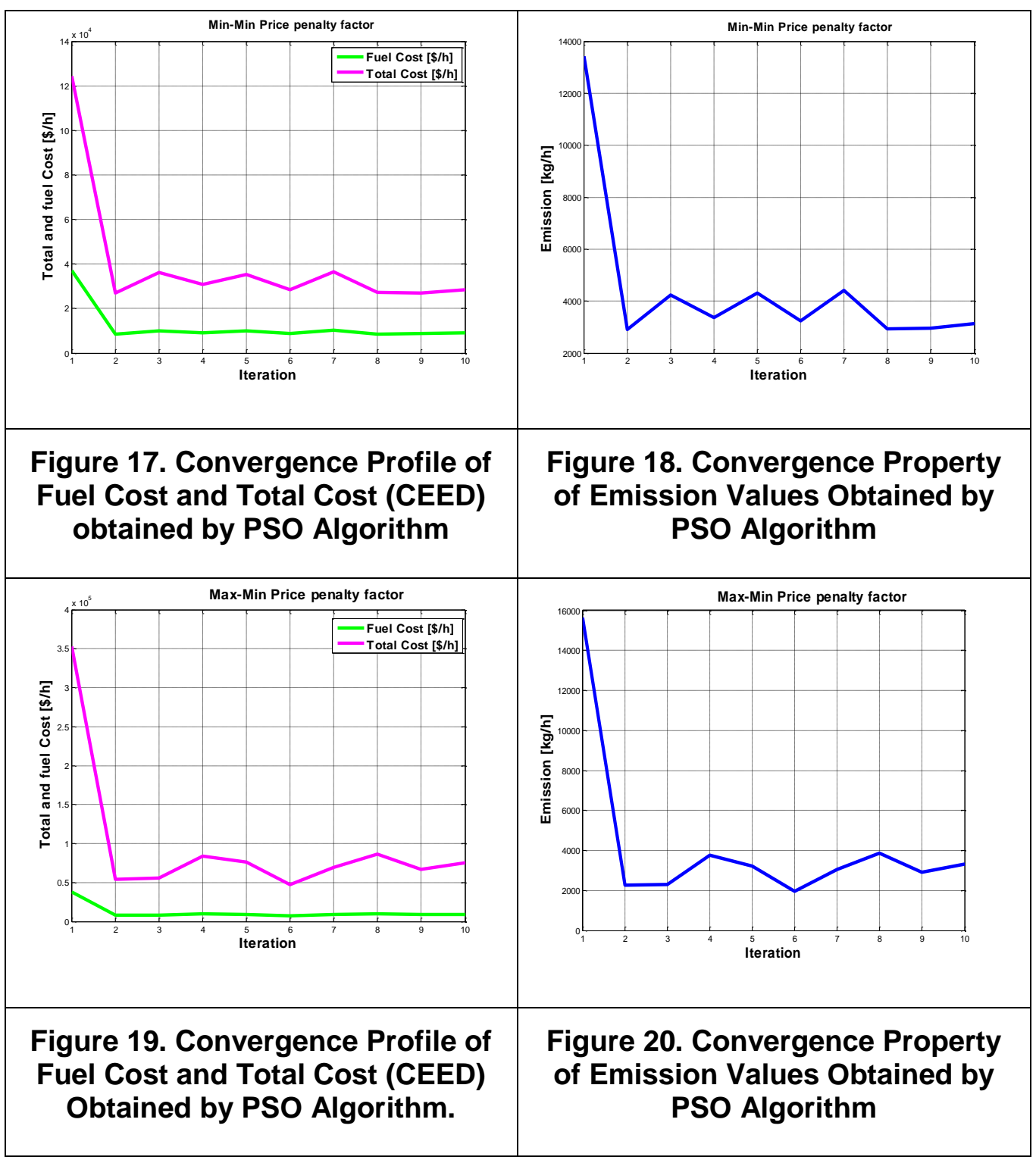

Results of Table 8 show an acceptable improvement in the transmission power loss, fuel cost, pollution control and total fuel cost CEED of the system, with acceptable computation time when using the Min-Max price penalty factor in comparison with the Max-Max, Min-Min, and Max-Min penalty factor, which demonstrates that the proposed algorithm has more ability to find the optimal points in a search space compared to data from SONELGAZ in [15].

Figure 13 show clearly that the convergence of fuel and total cost of PSO when using Min-Max price penalty factor is better than other price penalty factor, the cost of generation for Min-Max PPF at iteration 2 is lower than other PPF and emission values at the same iteration.

\subsubsection{Case study 3: Eleven Generator Systems}

This system contains 11 thermal generating units and the characteristics of the units are given in table 10 and 11 respectively. The considered load demand for the system is 2500 MW. But the $B$ loss coefficient matrix is neglected because of limitation in space. This example has quite a large problem search space compared to the previous examples. 
After applying and executing the proposed algorithm to the CEED problem, the optimal solution of the eleven generators is given in Table 12. Figures 21-28 shows the convergence of values for the fitness function and emission during iterations.

Table 10. Power Generation and Cost Coefficients of Eleven Generator System

\begin{tabular}{|l|l|l|l|l|}
\hline$P_{G, \max }[\mathrm{MW}]$ & $P_{G, \min }[\mathrm{MW}]$ & $\mathrm{a}_{\mathrm{i}}\left[\$ / \mathrm{MW}^{2} \mathrm{~h}\right]$ & $\mathrm{b}_{\mathrm{i}}[\$ / \mathrm{MWh}]$ & $\mathrm{c}_{\mathrm{i}}[\$ / \mathrm{h}]$ \\
\hline 250 & 20 & 0.00762 & 1.92699 & 387.85 \\
\hline 210 & 20 & 0.00838 & 2.11969 & 441.62 \\
\hline 250 & 20 & 0.00523 & 2.19169 & 422.57 \\
\hline 300 & 60 & 0.00140 & 2.01983 & 552.50 \\
\hline 210 & 20 & 0.00154 & 2.22181 & 557.75 \\
\hline 300 & 60 & 0.00177 & 1.91528 & 562.18 \\
\hline 215 & 20 & 0.00195 & 2.10681 & 568.39 \\
\hline 455 & 100 & 0.00106 & 1.99138 & 682.93 \\
\hline 455 & 100 & 0.00117 & 1.99802 & 741.22 \\
\hline 460 & 110 & 0.00089 & 2.12352 & 617.83 \\
\hline 465 & 110 & 0.00098 & 2.10487 & 674.61 \\
\hline
\end{tabular}

Table 11. Pollution Coefficients of Eleven-Generator System

\begin{tabular}{|l|l|l|}
\hline$d_{i}\left[\mathrm{~kg} / \mathrm{MW}^{2} \mathrm{~h}\right]$ & $\mathrm{e}_{\mathrm{i}}[\mathrm{kg} / \mathrm{MWh}]$ & $\mathrm{f}_{\mathrm{i}}[\mathrm{kg} / \mathrm{h}]$ \\
\hline 0.00419 & -0.67767 & 33.93 \\
\hline 0.00461 & -0.69044 & 24.62 \\
\hline 0.00419 & -0.67767 & 33.93 \\
\hline 0.00683 & -0.54551 & 27.14 \\
\hline 0.00751 & -0.40060 & 24.15 \\
\hline 0.00683 & -0.54551 & 27.14 \\
\hline 0.00751 & -0.40060 & 24.15 \\
\hline 0.00355 & -0.51116 & 30.45 \\
\hline 0.00417 & -0.56228 & 25.59 \\
\hline 0.00355 & -0.41116 & 30.45 \\
\hline 0.00417 & -0.56228 & 25.59 \\
\hline
\end{tabular}

Table 12. The Best Results of Eleven Generators System

\begin{tabular}{|l|c|c|c|c|}
\hline criterion & Min-Max & Max-Max & Min-Min & Max-Min \\
\hline $\boldsymbol{P}_{\mathbf{1}}[\boldsymbol{M W}]$ & 89.425 & 223.67 & 220.42 & 221.14 \\
\hline $\boldsymbol{P}_{\mathbf{2}}[\boldsymbol{M W}]$ & 172.03 & 210 & 210 & 126.71 \\
\hline $\boldsymbol{P}_{\mathbf{3}}[\boldsymbol{M W}]$ & 213.3 & 104.91 & 250 & 235.01 \\
\hline $\boldsymbol{P}_{\mathbf{4}}[\boldsymbol{M W}]$ & 264.93 & 215.28 & 104.95 & 137.2 \\
\hline $\boldsymbol{P}_{\mathbf{5}}[\boldsymbol{M W}]$ & 100.98 & 204.37 & 193.71 & 135.22 \\
\hline $\boldsymbol{P}_{\mathbf{6}}[\boldsymbol{M W}]$ & 183.27 & 79.55 & 236.2 & 170.84 \\
\hline
\end{tabular}




\begin{tabular}{|l|c|c|c|c|}
\hline $\boldsymbol{P}_{\mathbf{7}}[\mathbf{M W}]$ & 190.38 & 215 & 115.24 & 160.34 \\
\hline $\boldsymbol{P}_{\mathbf{8}}[\mathbf{M W}]$ & 359.79 & 384.03 & 243.33 & 416.68 \\
\hline $\boldsymbol{P}_{\mathbf{9}}[\mathbf{M W}]$ & 299 & 279.88 & 346.96 & 256.68 \\
\hline $\boldsymbol{P}_{\mathbf{1 0}}[\mathbf{M W}]$ & 329.33 & 349.34 & 250.73 & 252.92 \\
\hline $\boldsymbol{P}_{\mathbf{1 1}}[\mathbf{M W}]$ & 298.2 & 233.97 & 328.47 & 387.26 \\
\hline Total output & 2500 & 2500 & 2500 & 2500 \\
\hline $\begin{array}{l}\text { Load } \\
\text { demand }\end{array}$ & 2500 & 2500 & 2500 & 2500 \\
\hline $\begin{array}{l}\text { Fuel Cost } \\
\text { [\$/h] }\end{array}$ & $\mathbf{1 2 5 8 1}$ & $\mathbf{1 2 8 1 7}$ & $\mathbf{1 2 9 9 6}$ & $\mathbf{1 2 7 7 4}$ \\
\hline $\begin{array}{l}\text { Emission } \\
{[\mathrm{kg} / \mathrm{h}]}\end{array}$ & $\mathbf{1 9 7 1 . 4}$ & $\mathbf{1 9 7 3 . 2}$ & $\mathbf{1 8 1 8 . 1}$ & $\mathbf{1 8 5 7 . 3}$ \\
\hline $\begin{array}{l}\text { Total Cost } \\
\text { [\$/h] }\end{array}$ & $\mathbf{1 6 0 7 2}$ & $\mathbf{2 1 0 7 0}$ & $\mathbf{1 0 0 9 7 0}$ & $\mathbf{2 0 1 3 4 0}$ \\
\hline Temps [S] & 0.490277 & 0.362776 & 0.356488 & 0.379458 \\
\hline
\end{tabular}

Table 13. Graphical Representation of the Best-Obtained Simulink Results for Eleven-Generator System

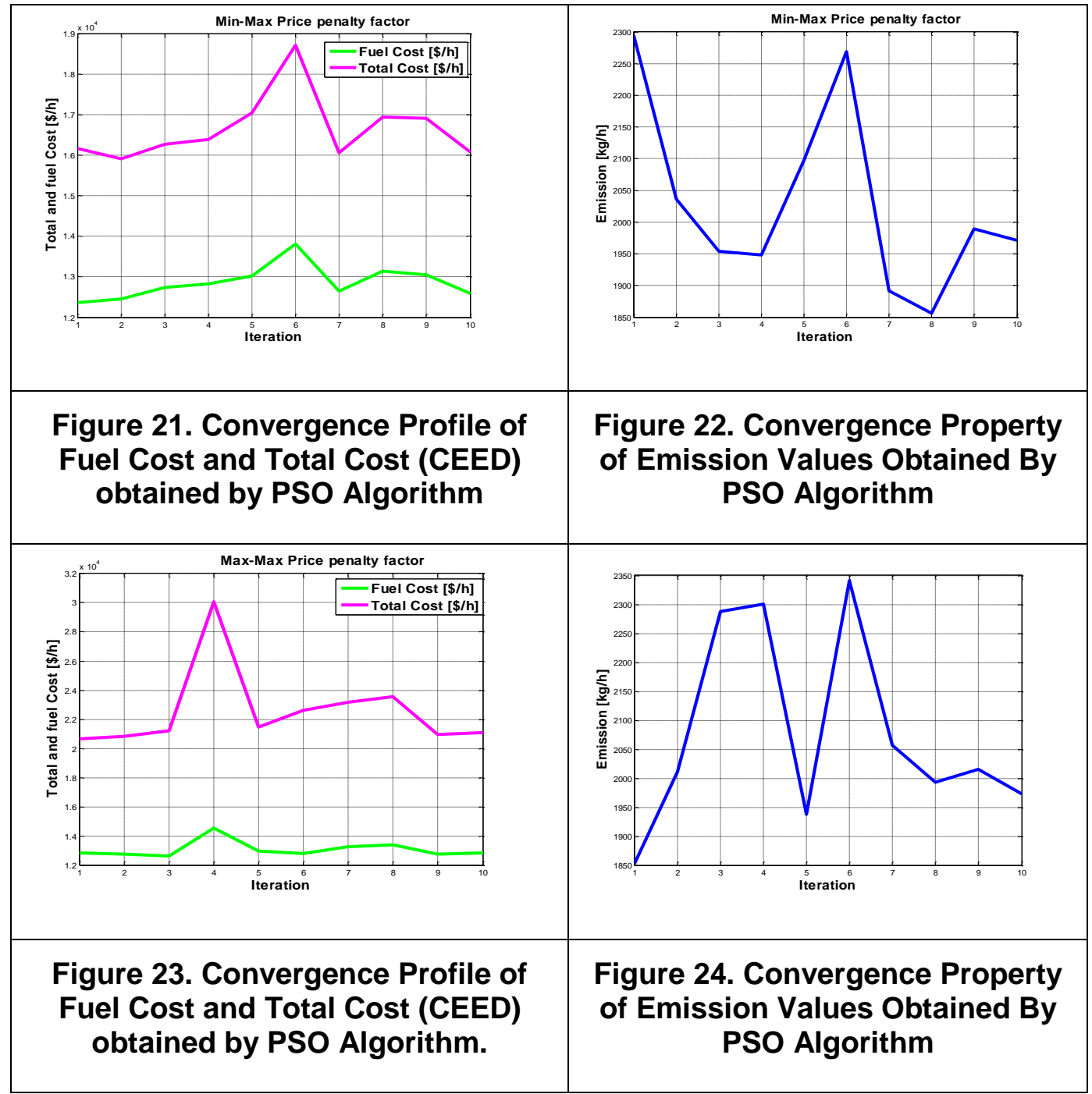




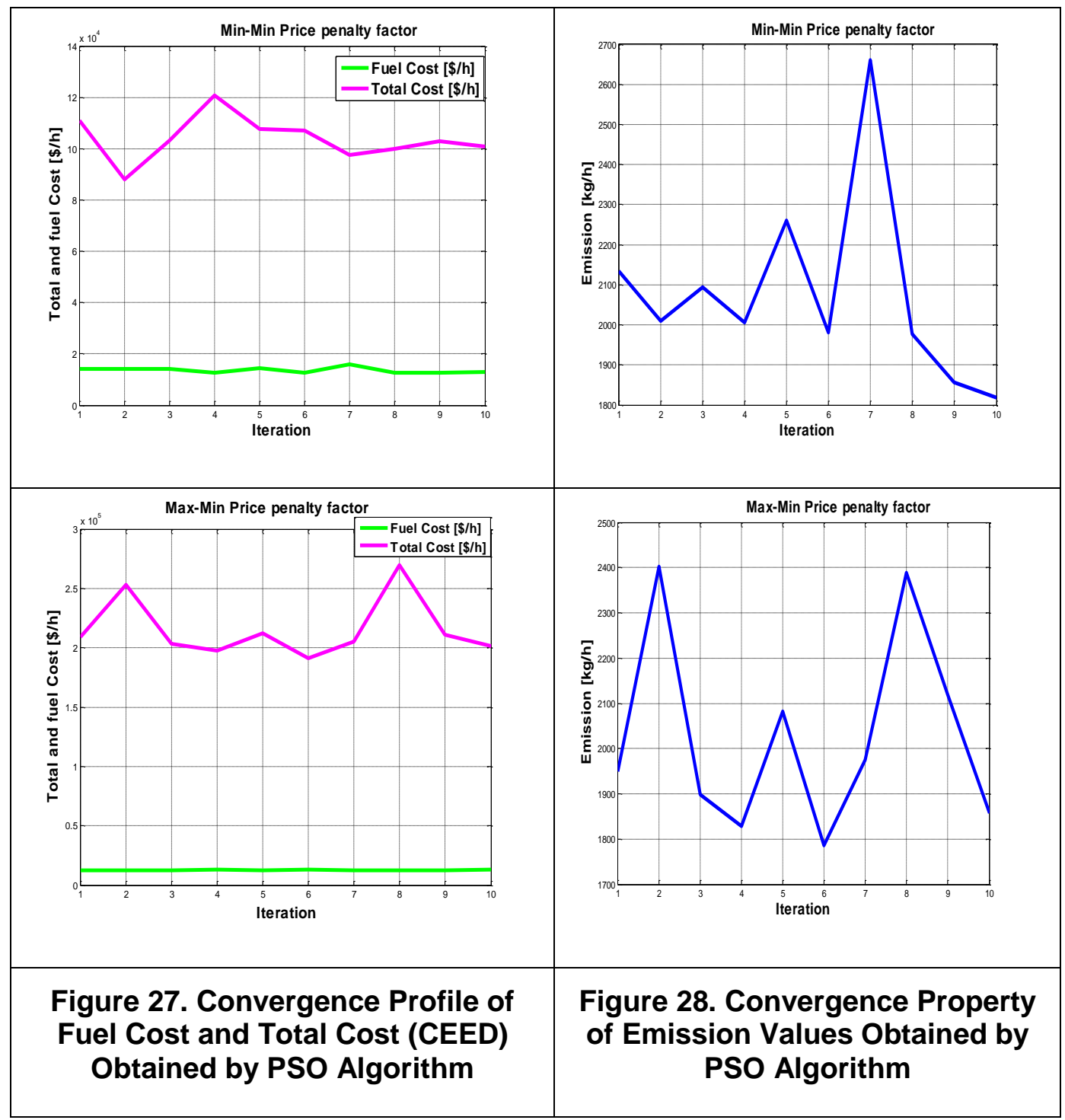

The Table 12 shows that the proposed algorithm can find a better results value for the problem when using Min-Max price penalty factor compared to the other price penalty factor such as Max-Max, Min-Min, and Max-Min. The intense of convergence in figures 21-28, also demonstrate that the proposed algorithm is able to find the solution of the problem in large search space more efficiently and faster

Figure 21 and 22 shows that the results obtained with proposed approach PSO when using Min-Max PPF the fuel and total cost are better than those obtained by the other PPF and also for emission values.

\section{Conclusions}

In this paper, The Algorithm of Particle Swarm Optimization was proposed to solve the CEED problem using four different penalty factors which are Min-Max, Max-Max, MinMin and Max-Min price penalty factors, and their effectiveness is questioned by testing the Algorithm on IEEE-30 bus system, Real West Algeria 22-bus system with 7 generators and eleven generator systems. On the basis of results obtained, the PSO algorithm has been successfully implemented to solve optimal power flow problem for minimization of the total cost of the generation, the cost of pollution level control and the active power loss. Simulation results, show that the proposed method works, equally well 
for both small and large case studies and it has been shown that the algorithm can converge faster when using Min-Max price penalty factor than the other price penalty factors.

\section{Acknowledgment}

Authors would like to thank the heads of Laboratory of Analysis, Control and Optimization of Electro-Energetic Systems (CAOSEE) and Smart Grids the renewable energies (ENERGARID) at the university TAHRI Mohammed of Béchar (Algeria).

\section{References}

[1] S. Anjum, "Multi Objective Economic Emission Dispatch Using Modified Multi Objective Particle Swarm Optimization", Master thesis, Thapar University, Punjab, India, (2013).

[2] H. Wang, C. E. Murillo-Sanchez, R. D. Zimmerman and R. J. Thomas, "On Computational Issues of Market-Based Optimal Power Flow”, IEEE Transactions on Power Systems, vol. 22, no. 3, (2007), pp. 1185-1193.

[3] S. Dhanalakshmi, S. Kannan, K. Mahadevan and S. Baskar, "Application of modified NSGA-II algorithm to Combined Economic and Emission Dispatch problem", Electrical Power and Energy Systems, vol. 33, (2011), pp. 992-1002.

[4] H. Saadat, "Power Flow analysis", Milwaukee School of Engineering, McGraw-Hill Companies.

[5] S. Krishnamurthy and R. Tzoneva, "Impact of Price Penalty Factors on the Solution of the Combined Economic Emission Dispatch Problem using Cubic Criterion Functions", IEEE Power \& Energy Society General Meeting, Energy Horizons - Opportunities and Challenges, Manchester Grand Hyatt, San Diego, California, USA, (2012).

[6] S. Krishnamurthy and R. Tzoneva, "Comparative Analyses of Min-Max and Max-Max Price Penalty Factor Approaches for Multi Criteria Power System Dispatch Problem Using Lagrange's Method”, International conference on recent advancements in Electrical, Electronics and Control Engineering, Sivakasi,India, (2011).

[7] S. Krishnamurthy and R. Tzoneva, "Comparative Analyses of Min-Max and Max-Max Price Penalty Factor Approaches for Multi Criteria Power System Dispatch Problem with valve point effect Using Lagrange's Method", International Conference on Power and Energy Systems (1CPS - 2011), India, (2011).

[8] R.H. Bhesdadiya, N. Jangir, M. H. Pandyan Pradeep Jangir, I. N. Trivedi and A. Kumar, “ Price Penalty factors Based Approach for Combined Economic Emission Dispatch Problem Solution using Dragonfly Algorithm", 978-1-4673-9925-8/16/\$31.00 @2016 IEEE.

[9] D. Hamza Zerigat, L. Benasla, A. Belmadani and M. Rahli, "Solution of Combined Economic and Emission Dispatch problems using Galaxy-based Search Algorithm”, J. Electrical Systems 9-4, (2013), pp. $468-480$

[10] S. Krishnamurthy, "Devlopment of Decomposition Methods for Solution of a Multiarea Power Dispatch Optimisation Problem", doctoral thesis, (2013).

[11] S. Krishnamurthy and R. Tzoneva, "Impact of Price Penalty Factors on the Solution of the Combined Economic Emission Dispatch Problem using Cubic Criterion Functions", IEEE, 978-1-4673-27299/12/\$31.00, (2012).

[12] S. Krishnamurthy and R. Tzoneva, "Comparative Analyses of Min-Max and Max-Max Price Penalty Factor Approaches for Multi Criteria Power System Dispatch Problem Using Lagrange's Method ”, IEEE, 978-1-4577-2149-6/11/\$26.00, (2011).

[13] J. Kennedy and R. C. Eberhart, "Particle swarm optimization", 1995, pp. 1942-1948.

[14] J. Blondin, "Particle Swarm Optimization Applications in Parameterization of Classifiers", Armstrong Atlantic State University.

[15] Y. Mouloudi, M. Amine Meziane, A. Laoufi, B. Bouchiba, O. Harisi, "A Swarm Algorithm Intelligent Optimization PSO in Power Network Real", West Algeria 220 kV ", Electrotehnică, Electronică, Automatică, vol. 64, n0. 1, (2016). 


\section{Authors}

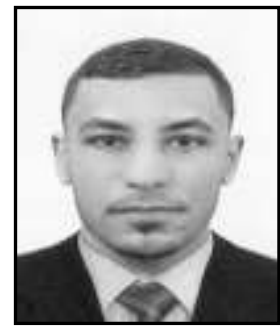

Mohammed Amine Meziane, he was born in 1992 at Ain Sefra -Naama-Algeria. In 2015, he received the state master degree in Electrical Engineering from the University of Bechar, Algeria. He is currently a PhD. Student from the University of Bechar, Algeria, Faculty Technology. His areas of interest are stability improvement and optimization in power network, FACTS systems, power filters and applications of power electronics. Correspondence address: Dept. Science and Technology "Electrical Engineering", Faculty of Technology, Bechar University, BP 417, 08000 Bechar, Algeria,

E-mail: aminemohmeziane@gmail.com.

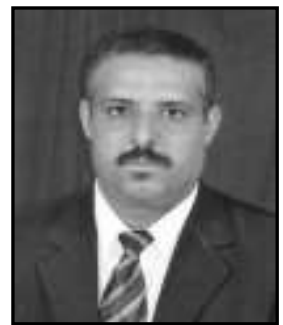

Youssef Mouloudi, he received the state engineer degree in Electrical Engineering in 2006 from the University of Bechar and M.S. and Ph.D. from Bechar University, Algeria. in 2009 and 2013, respectively. He was working at SONELGAZ "Algeria Electrical Society" since 1995. Currently, he is an assistant professor of electrical engineering, Faculty Technology at Bechar University, Algeria. His areas of interest are FACTS systems, power filters, applications of power electronics, and stability improvement. Correspondence address: Dept. Science and Technology "Electrical Engineering", Faculty of Technology, Bechar University, BP 417, 08000 Bechar, Algeria,

E-mail: mouloudiyoussef@yahoo.fr 
International Journal of Control and Automation

Vol. 11, No. 2 (2018) 